\title{
Relationship between periodontal diseases and bone diseases in some bone disease patients.
}

\author{
Yu-Hee Lee ${ }^{1}$, Jung-Ok Choi², Seoul-Hee Nam $^{3 *}$ \\ ${ }^{1}$ Department of Dental Hygiene, Taegu Science University, Taegu, Republic of Korea \\ ${ }^{2}$ Department of Dental Hygiene, Youngsan University, Yangsan, Republic of Korea \\ ${ }^{3}$ Department of Dental Hygiene, College of Health Science, Kangwon National University, Samcheok-si, Republic of \\ Korea
}

\begin{abstract}
The purpose of this study was to identify factors that cause periodontal disease in patients with bone disease. The prevalence of periodontal disease in patients with osteoarthritis was investigated in 705 patients with osteoarthritis or osteoporosis among 5,945 adult specimens excluding the under 19 years of age based on the National Health and Nutrition Research Institute. The prevalence of periodontal diseases was found to be significantly different according to general characteristics of some bone disease and oral characteristics. As a result, the prevalence of periodontal disease tended to decrease with increasing income. The education level was similar to that of the undergraduate $(\mathbf{4 3 . 0 \%})$ and the middle school graduate $(\mathbf{4 5 . 4 \%})$, and the prevalence of periodontal disease tended to decrease as the number of high school graduates $(31.1 \%)$ and college graduates $(24.4 \%)$. The prevalence of periodontal disease was higher in patients without hypertension $(33.8 \%)$ than in those without hypertension $(\mathbf{4 6 . 1 \% )}$ ). The prevalence of periodontal disease was higher $(28.5 \%)$ than that of good oral health $(46.8 \%)$. The prevalence of periodontal disease was significantly higher $(\mathbf{p}<0.05)$. The results of multiple logistic regression analysis were used to examine factors affecting periodontal disease. The results of the multiple logistic regression analysis showed that the higher the incomes, the higher the blood pressure, the better the subjective health condition, respectively. These results suggest that income levels, chronic disease management and use of oral hygiene products are effective in increasing the prevalence of periodontal disease and increasing oral health status in patients with bone disease. Therefore, dental hygienists should make oral health and oral hygiene education suitable for chronic disease management as well as oral health knowledge and make efforts to promote oral health.
\end{abstract}

Keywords: Bone disease, National health and nutrition research institute, Oral care product, Periodontal disease. Accepted on June 19, 2018

\section{Introduction}

Osteoporosis is a systemic skeletal disorder that leads to increased bone flexibility due to decreased bone mass and microstructural destruction of the bone. In addition, it easily causes fracture even from a minor impact. In 1955, osteoporosis accounted for $18 \%$ of the total population, while $27 \%$ in 2010 and $35 \%$ by 2020 are estimated to be the risk group for osteoporosis [1]. The incidence and severity of osteoporosis increase with age, and it is expected that the number of patients will increase by the increase of average life expectancy in the future [2]. In addition to osteoporosis, osteoarthritis is a musculoskeletal disorder that affects approximately $10 \%$ of the world's population [3]. It is known to be accompanied by bone destruction associated with inflammatory cytokines [4].
Periodontal disease is an inflammatory disease that occurs in the tissues that surround the teeth. It is the major cause of tooth loss as gingival recession, formation of paradental cyst, and destruction of the periodontal ligaments and alveolar bone progress [5]. It is one of the chronic diseases ranked as third in the frequency of medical institution utilization [6]. According to the 2015 Korea National Health and Nutrition Examination Survey (KNHANES), $16.5 \%$ of males and $14.5 \%$ of females in their 30 s were required to treat periodontal diseases even at a young age, and approximately $50 \%$ of males and $40 \%$ of females in their 50s or older showed a higher prevalence with the increase of age [7]. Alveolar bone loss is a typical symptom of periodontal disease, and severe osteoporosis has been reported to increase the severity of periodontal disease [8-11]. Many studies have been conducted on the relationship between bone disease and periodontal disease in the past. Klemetti [12] reported that osteoporosis is deeply involved in the alveolar 
bone resorption process, and Kribbs [13] mentioned that the density of mandibular bone was reduced and the cortical bone plate was thinned in persons with osteoporosis. It has also been reported that periodontitis and rheumatoid arthritis may be associated with each other in that inflammatory cell infiltration occurs, and they are mediated by cytokines $[14,15]$.

The morbidity rates of bone disease and periodontal disease increase with age in both men and women worldwide, and these diseases have been studied in various ways [16]. As the population ages along with the development of medical science, the management of these two diseases, which increase rapidly with age, can be regarded as one of the essential conditions for a healthy life. Unlike in the past, the concept of health is understood in a comprehensive manner; therefore, it cannot be regarded as perfect health without proper oral health care [17]. If the teeth are lost due to oral diseases, it will result in a reduced chewing ability, and the range of food for consumption becomes limited, thereby leading to lowered quantity and quality of meals, which may result in the difficulty of maintaining good health and fitness.

In this regard, bone disease is a complication caused by fracture and bone destruction, thereby leading to high mortality and morbidity rates, and causing significant socioeconomic loss in medical costs. It is also considered to be a very serious disease for adults [18]. Hormonal imbalances and immune functions that change during this period may also increase the risk of periodontal diseases $[19,20]$.

This study aims to investigate the prevalence of periodontal diseases in adults with bone disease by using the national data of the Korea National Health and Nutrition Examination Survey (KNHANES VI-3) based on the classification of data according to the general characteristics (e.g, gender, age, income, education level, and marital status), health care behaviors (e.g, BMI, subjective health state, smoking, drinking, hypertension, diabetes, menopause, etc.), and oral health characteristics (e.g, dental checkup status, dental visit, number of tooth brushing, use of dental auxiliary products, etc.), and analyzing them from multiple aspects. It also aims to provide fundamental data to maintain a healthy life in the aging society and improve the quality of life by lowering the incidence of periodontal diseases in patients with bone disease.

\section{Materials and Methods}

\section{Study subjects}

This study used raw data from the 6th Korea National Health and Nutrition Examination Survey (KNHANES VI-3) in 2015. Among a total of 7,380 samples, excluding the 1,435 samples under 19 years of age, 5,945 adult samples were extracted. Among them, 926 samples with osteoarthritis or osteoporosis were extracted. Excluding 221 patients, who had missing values in the main variables, 705 adults with osteoarthritis or osteoporosis were finally selected as the study subjects.

\section{Survey methods}

For this study, the IRB review was exempted (INJE 2017-08-005-003). From the raw data of KNHANES VI-3, gender, age, income, education level, marital status, subjective health state, Body Mass Index (BMI), smoking, drinking, hypertension, diabetes, menopause, calcium intake, stress, depression, suicidal ideation, dental check-up status, dental visit, gum disease treatment, tooth brushing status by period, subjective oral health, use of dental floss, use of interdental toothbrush, use of mouthwash, and presence of periodontal disease were utilized.

The age was divided into 19 to 29,30 to 39,40 to 49,50 to 59 , 60 to 69 , and 70 and older. The marital status was classified into 'married-spouse present', 'married-no spouse', and 'unmarried'. For the subjective health state, 'very bad' and 'bad' were classified as 'bad', while 'average', 'good', and 'very good' were classified as 'good'. For the Body Mass Index (BMI), BMI values below 18.5 were classified as 'underweight', BMI values of more than 18.5 and less than 23.0 were classified as 'normal', BMI values of more than 23.0 and less than 25.0 were classified as 'overweight', and BMI values of 25.0 or more were classified as 'obesity'. Smoking was categorized into 'current smoker', 'past smoker', and 'nonsmoker'. Drinking was categorized into 'not drinking alcohol' and 'drinking alcohol' based on whether or not they consumed an alcoholic beverage for more than once a month. Calcium intake was categorized into intake of the recommended amount and intake of less than the recommended amount based on the recommended amount of calcium intake by age group suggested by the Korean Nutrition Society. The number of tooth brushing was calculated by summing up the periods of tooth brushing based on the tooth brushing status at each period, and the calculated number of tooth brushing was classified into $0-1,2,3$, and 4 or more times. For the selfperceived oral health status, 'very poor' and 'poor' were classified as 'poor', while 'average', 'good', and 'very good' were classified as 'good' in order to perform statistical testing. The remaining variables other than these were used for the analysis without conversion.

\section{Statistical analysis}

In this study, a complex sample analysis was conducted because it used the raw data from KNHANES, which was extracted by using a stratified two-stage sampling design, rather than a simple random sampling design. Stratification and clustering variables were applied, and the complex sample design was made by applying the questionnaire and examination survey weighting.

Frequency analysis and descriptive statistics were performed in order to investigate the general characteristics and oral characteristics of the subjects. Chi-square tests were performed in order to identify the prevalence of periodontal diseases according to major variables. Meanwhile, a multiple logistic regression analysis was performed in order to examine the 
influences of general and oral characteristics of subjects with osteoporosis or osteoarthritis on periodontal diseases.

For the statistical analysis of this study, SPSS version 22.0 (IBM corp, Armonk, NY, USA) was used.

\section{Results}

\section{Prevalence of periodontal diseases according to the health behaviors of the subjects}

Frequency analysis and descriptive statistics were calculated in order to identify the general characteristics and health behaviors of the subjects. In terms of gender, 119 males $(19.4 \%)$ and 586 females $(80.6 \%)$ were included. As for the age, 19-29 y was comprised of 6 persons (1.6\%), 30-39 y was comprised of 9 persons $(2.6 \%), 40-49$ y was comprised of 30 persons (6.6\%), 50-59 y was comprised of 145 persons (24.9\%), 60-69 y was comprised of 245 persons $(30.2 \%)$, and $70 \mathrm{y}$ or older was comprised of 270 persons (34.1\%). As for the income, 259 persons (34.9\%) fell under the lower level, 179 persons $(23.5 \%)$ fell under the lower-middle level, 157 persons $(23.6 \%)$ fell under the upper-middle level, and 110 persons $(18.0 \%)$ fell under the upper level. In terms of the education level, elementary school or lower was comprised of 390 persons $(51.3 \%)$, middle school was comprised of 114 persons $(16.6 \%)$, high school was comprised of 133 persons $(20.4 \%)$ and college or higher was comprised of 68 persons $(11.6 \%)$. As for the marital status, married-spouse present was comprised of 452 persons $(65.2 \%)$, married-no spouse was comprised of 243 persons $(32.3 \%)$, and unmarried was comprised of 10 persons $(2.5 \%)$. As for the subjective health status, 301 persons $(42.3 \%)$ answered bad, while 404 persons $(57.7 \%)$ answered good. In terms of BMI, underweight was comprised of 14 persons (2.4\%), normal was comprised of 197 persons $(27.9 \%)$, overweight was comprised of 178 persons (24.6\%), and obesity was comprised of 315 persons $(45.1 \%)$. As for smoking, 47 persons $(8.5 \%)$ were current smokers, 89 persons $(13.7 \%)$ were past smokers, and 569 persons $(77.8 \%)$ were non-smokers. As for drinking, 484 persons (65.6\%) were not drinking alcohol, while 221 persons (34.4\%) were drinking alcohol.

Among the subjects, 322 persons (40.5\%) had hypertension, while 383 persons $(59.5 \%)$ did not have hypertension; and 109 persons $(14.4 \%)$ were diabetic, while 596 persons $(85.6 \%)$ were not diabetic. Furthermore, 533 persons $(69.8 \%)$ experienced menopause, while 172 persons (30.2\%) did not experience menopause; and 71 persons $(10.2 \%)$ ingested the recommended amount of calcium, while 634 persons $(89.8 \%)$ did not ingest the recommended amount of calcium. In addition, 187 persons (29.4\%) experienced a lot of stress, while 518 persons $(70.6 \%)$ were less stressed; 142 persons $(20.0 \%)$ experienced depressive symptoms, while 563 persons $(80.0 \%)$ did not experience depressive symptoms; and 56 persons $(8.9 \%)$ had suicidal ideation, while 649 persons $(91.1 \%)$ did not have suicidal ideation.
Chi-square tests were conducted in order to verify whether there was a significant difference in the prevalence of periodontal diseases according to the general and oral characteristics of the subjects.

As a result, the prevalence of periodontal diseases was significantly different according to income, education level, hypertension, and subjective health status of patients with osteoarthritis or osteoporosis $(\mathrm{p}<0.05)$.

The prevalence of periodontal diseases according to income was $46.0 \%$ for the lower level, $45.1 \%$ for the lower-middle level, $30.2 \%$ for the upper-middle level, and $27.9 \%$ for the upper level, thereby indicating that the prevalence was likely to decrease as the income increased. As for the prevalence of periodontal diseases according to education level, the prevalence was similar in elementary school or lower $(43.0 \%)$ and middle school graduate (45.4\%), and it was likely to become lower as the education level increased to high school $(31.1 \%)$ and college or higher $(24.4 \%)$. In terms of hypertension, the prevalence of periodontal diseases was higher in patients with hypertension $(46.1 \%)$ than in those without hypertension $(33.8 \%)$. In regard to the subjective oral health status, the prevalence of periodontal diseases was higher when the subjective oral health status was bad $(46.8 \%)$ than when it was good (28.5\%) (Table 1).

Table 1. Difference of periodontal disease according to general and oral behavior $(N=705)$.

\begin{tabular}{|c|c|c|c|c|c|}
\hline \multirow[t]{2}{*}{ Variables } & \multirow[t]{2}{*}{ Group } & \multirow[t]{2}{*}{$\mathrm{N}(\%)$} & \multicolumn{2}{|c|}{ Periodontal disease } & \multirow[t]{2}{*}{$\mathbf{p}^{*}$} \\
\hline & & & No & Yes & \\
\hline \multirow[t]{2}{*}{ Sex } & Male & $119(19.4)$ & $58(56.5)$ & $61(43.5)$ & 0.312 \\
\hline & Female & $586(80.6)$ & $364(62.3)$ & $222(37.7)$ & \\
\hline \multirow[t]{6}{*}{ Age } & $19-29$ & $6(1.6)$ & $6(100.0)$ & $0(0.0)$ & 0.128 \\
\hline & $30-39$ & $9(2.6)$ & $7(72.8)$ & $2(27.2)$ & \\
\hline & $40-49$ & $30(6.6)$ & $21(67.2)$ & $9(32.8)$ & \\
\hline & $50-59$ & $145(24.9)$ & $93(68.1)$ & $52(31.9)$ & \\
\hline & $60-69$ & $245(30.2)$ & $146(58.2)$ & $99(41.8)$ & \\
\hline & 70 & $270(34.1)$ & $149(55.0)$ & $121(45.0)$ & \\
\hline \multirow[t]{4}{*}{ Income } & Low & $259(34.9)$ & $138(54.0)$ & $121(46.0)$ & 0.006 \\
\hline & Mid-low & $179(23.5)$ & $97(54.9)$ & $82(45.1)$ & \\
\hline & Mid-high & $157(23.6)$ & $107(69.8)$ & $50(30.2)$ & \\
\hline & High & $110(18.0)$ & $80(72.1)$ & $30(27.9)$ & \\
\hline \multirow[t]{4}{*}{ Education } & $\begin{array}{l}\leq \\
\text { Elementary }\end{array}$ & $390(51.3)$ & $220(57.0)$ & $170(43.0)$ & 0.022 \\
\hline & Middle & $114(16.6)$ & $61(54.6)$ & $53(45.4)$ & \\
\hline & High & $133(20.4)$ & 90 (68.9) & $43(31.1)$ & \\
\hline & $\leq$ College & $68(11.6)$ & $51(75.6)$ & $17(24.4)$ & \\
\hline \multirow[t]{2}{*}{ Marriage } & Spouse & $452(65.2)$ & $283(64.6)$ & $169(35.4)$ & 0.169 \\
\hline & No spouse & $243(32.3)$ & $132(54.1)$ & $111(45.9)$ & \\
\hline
\end{tabular}




\begin{tabular}{|c|c|c|c|c|c|}
\hline & Not married & $10(2.5)$ & $7(64.7)$ & $3(35.3)$ & \\
\hline \multirow[t]{2}{*}{ Subjective health } & Bad & 301 (42.3) & $191(63.6)$ & $110(36.4)$ & 0.351 \\
\hline & Good & $404(57.7)$ & $231(59.5)$ & $173(40.5)$ & \\
\hline \multirow[t]{4}{*}{ BMI } & Low weight & $14(2.4)$ & $7(41.0)$ & $7(59.0)$ & 0.484 \\
\hline & Normal & $197(27.9)$ & $121(62.0)$ & $76(38.0)$ & \\
\hline & Overweight & $178(24.6)$ & $100(64.1)$ & 78 (35.9) & \\
\hline & Obesity & $315(45.1)$ & $193(60.0)$ & $122(40.0)$ & \\
\hline \multirow[t]{3}{*}{ Smoking } & Current & $47(8.5)$ & $21(49.2)$ & $26(50.8)$ & 0.21 \\
\hline & Past & $89(13.7)$ & $47(57.4)$ & $42(42.6)$ & \\
\hline & Non-smoker & $569(77.8)$ & 354 (63.2) & $215(36.8)$ & \\
\hline \multirow[t]{2}{*}{ Drinking } & No & $484(65.6)$ & $290(61.7)$ & $194(38.3)$ & 0.749 \\
\hline & Yes & $221(34.4)$ & $132(60.2)$ & $89(39.8)$ & \\
\hline \multirow[t]{2}{*}{ Hypertension } & No & $383(59.5)$ & $241(66.2)$ & $142(33.8)$ & 0.009 \\
\hline & Yes & $322(40.5)$ & $181(53.9)$ & $141(46.1)$ & \\
\hline \multirow[t]{2}{*}{ Diabetes } & No & $596(85.6)$ & $350(60.0)$ & $246(40.0)$ & 0.196 \\
\hline & Yes & $109(14.4)$ & $72(68.0)$ & $37(32.0)$ & \\
\hline \multirow[t]{2}{*}{ Menopause } & Men or no & $172(30.2)$ & $96(60.8)$ & $76(39.2)$ & 0.903 \\
\hline & Yes & $533(69.8)$ & $326(61.4)$ & $207(38.6)$ & \\
\hline \multirow[t]{2}{*}{ Calcium intake } & Not enough & $634(89.8)$ & $378(60.9)$ & $256(39.1)$ & 0.671 \\
\hline & Enough & $71(10.2)$ & $44(63.8)$ & $27(36.2)$ & \\
\hline \multirow[t]{2}{*}{ Stress } & No & $518(70.6)$ & $303(59.8)$ & $215(40.2)$ & 0.333 \\
\hline & Yes & $187(29.4)$ & 119 (64.6) & $68(35.4)$ & \\
\hline Depression & No & $563(80.0)$ & $336(61.4)$ & 227 (38.6) & 0.865 \\
\hline
\end{tabular}

\begin{tabular}{|c|c|c|c|c|c|c|}
\hline & & Yes & $142(20.0)$ & $86(60.5)$ & 56 (39.5) & \\
\hline \multirow{2}{*}{$\begin{array}{l}\text { Thought } \\
\text { suicide }\end{array}$} & \multirow[t]{2}{*}{ about } & No & 649 (91.1) & $388(60.8)$ & $261(39.2)$ & \multirow[t]{2}{*}{0.637} \\
\hline & & Yes & $56(8.9)$ & $34(65.0)$ & $22(35.0)$ & \\
\hline
\end{tabular}

Values are presented as number (weighted \%); ${ }^{*}$ calculated by chi-square test

\section{Prevalence of periodontal diseases according to the oral characteristics}

Among the subjects, 187 persons $(27.8 \%)$ had oral health check-up from the previous year, while 518 persons $(72.2 \%)$ did not have oral health check-up from the previous year; 419 persons $(59.4 \%)$ had a dental visit, while 286 persons $(40.6 \%)$ did not have a dental visit; and 138 persons $(19.8 \%$ ) had gum disease, while 567 persons $(80.2 \%)$ did not have gum disease. The number of tooth brushing was $0-1$ time in 81 persons (10.1\%), 2 times in 337 persons $(49.2 \%), 3$ times in 200 persons $(28.7 \%)$, and 4 or more times in 87 persons $(12.0 \%)$. The subjective oral health status was good in 313 persons (43.8\%) and bad in 392 persons (56.2\%). Moreover, 99 persons (16.1\%) used dental floss, while 606 persons $(83.9 \%)$ did not use dental floss; 95 persons $(15.1 \%)$ used an interdental toothbrush, while 610 persons $(84.9 \%)$ did not use an interdental toothbrush; and 155 persons (23.2\%) used a mouthwash, while 550 persons $(76.8 \%)$ did not use a mouthwash. Meanwhile, 283 persons $(38.8 \%)$ had periodontal diseases, while 422 persons $(61.2 \%)$ did not have any periodontal diseases.

The prevalence of periodontal diseases according to the use of dental floss was not significant based on the significance level of $5 \%$, but it showed a significance probability (p-value) close to the significance level (Table 2).

Table 2. Difference of periodontal disease according to oral characteristics $(N=705)$.

\begin{tabular}{|c|c|c|c|c|c|}
\hline \multirow[t]{2}{*}{ Variables } & \multirow[t]{2}{*}{ Group } & \multirow[t]{2}{*}{ N (\%) } & \multicolumn{2}{|c|}{ Periodontal disease } & \multirow[t]{2}{*}{$\mathbf{p}^{*}$} \\
\hline & & & No & Yes & \\
\hline \multirow[t]{2}{*}{ Dental examination in a year } & No & $518(72.2)$ & $309(60.6)$ & $209(39.4)$ & 0.631 \\
\hline & Yes & $187(27.8)$ & $113(62.8)$ & $74(37.2)$ & \\
\hline \multirow[t]{2}{*}{ Visit dental clinic in a year } & No & $286(40.6)$ & $166(59.6)$ & $120(40.4)$ & 0.536 \\
\hline & Yes & $419(59.4)$ & $256(62.3)$ & $163(37.7)$ & \\
\hline \multirow[t]{2}{*}{ Gum disease treatment } & No & $567(80.2)$ & $339(60.6)$ & $228(39.4)$ & 0.546 \\
\hline & Yes & $138(19.8)$ & $83(63.7)$ & $55(36.3)$ & \\
\hline \multirow[t]{4}{*}{ Tooth brushing frequency } & $0-1$ & $81(10.1)$ & $48(58.7)$ & $33(41.3)$ & 0.778 \\
\hline & 2 & $337(49.2)$ & $197(60.5)$ & $140(39.5)$ & \\
\hline & 3 & $200(28.7)$ & $123(61.0)$ & $77(39.0)$ & \\
\hline & 4 & $87(12.0)$ & $54(66.7)$ & $33(33.3)$ & \\
\hline Subjective & Good & $313(43.8)$ & $209(71.5)$ & $104(28.5)$ & $<0.001$ \\
\hline Oral health & Bad & $392(56.2)$ & $213(53.2)$ & $179(46.8)$ & \\
\hline
\end{tabular}




\begin{tabular}{|c|c|c|c|c|c|}
\hline \multirow[t]{2}{*}{ Use of floss } & No & 606 (83.9) & $349(59.2)$ & $257(40.8)$ & \multirow[t]{2}{*}{0.057} \\
\hline & Yes & $99(16.1)$ & $73(71.6)$ & $26(28.4)$ & \\
\hline \multirow[t]{2}{*}{ Use of interdental brush } & No & $610(84.9)$ & $359(61.1)$ & $251(38.9)$ & \multirow[t]{2}{*}{0.939} \\
\hline & Yes & $95(15.1)$ & $63(61.6)$ & $32(38.4)$ & \\
\hline \multirow[t]{2}{*}{ Use of gargle } & No & $550(76.8)$ & $319(60.3)$ & 231 (39.7) & \multirow[t]{2}{*}{0.417} \\
\hline & Yes & 155 (23.2) & $103(64.3)$ & $52(35.7)$ & \\
\hline
\end{tabular}

Values are presented as number (weighted \%); ${ }^{*}$ calculated by chi-square test.

\section{Analysis of factors affecting periodontal diseases}

Multiple logistic regression analysis was performed in order to test the factors affecting periodontal diseases in osteoarthritis or osteoporosis patients (Table 3). For the independent variables, income, education level, hypertension, and selfperceived oral health status, which were significant at the chisquare tests, were entered, and the use of dental flow that showed a significance probability close to the significance level was also included. For the dependent variables, the presence of periodontal diseases was entered, and 'normal (no periodontal diseases)' was set as the reference category.

As a result, the likelihood of having periodontal diseases was higher when the income level was lower $(\mathrm{OR}=1.581, \mathrm{p}<0.01)$ and lower-middle $(\mathrm{OR}=1.372, \mathrm{p}<0.01)$, as compared to the upper level. The education level did not significantly influence periodontal diseases. Patients with hypertension was 2.790 times more likely to develop periodontal diseases $(\mathrm{OR}=2.790$, $\mathrm{p}<0.001)$. When the subjective oral health status was good, the likelihood of having periodontal diseases was as low as approximately $42.6 \%$ level $(\mathrm{OR}=0.426, \mathrm{p}<0.001)$. In the case of using dental floss, the likelihood of having periodontal diseases was as low as approximately $62.8 \%$ level $(\mathrm{OR}=0.628$, $\mathrm{p}<0.001)$.

It was concluded that the patients with osteoarthritis or osteoporosis have a lower likelihood of having periodontal diseases when they have a higher income, no hypertension, good subjective health status, and a habit of using dental floss.

Table 3. Factors affecting periodontal disease of arthritis patients.

\begin{tabular}{lllll}
\hline Variables & & OR & $95 \%$ Cl & $\mathbf{p}^{*}$ \\
\hline Income & Low & 1.581 & $1.219-2.050$ & 0.001 \\
\cline { 2 - 5 } & Mid-low & 1.372 & $1.089-1.729$ & 0.008 \\
\cline { 2 - 5 } & Mid-high & 1.084 & $0.853-1.376$ & 0.509 \\
\cline { 2 - 5 } & High & 1 & & \\
\hline Education & $\leq$ Elementary & 1.096 & $0.828-1.449$ & 0.521 \\
\cline { 2 - 5 } & Middle & 1.291 & $0.981-1.699$ & 0.068 \\
\cline { 2 - 5 } & High & 1.124 & $0.884-1.428$ & 0.338 \\
\cline { 2 - 5 } & $\leq$ College & 1 & & \\
\hline Hypertension & No & 1 & & \\
\hline
\end{tabular}

\begin{tabular}{lllll} 
& Yes & 2.79 & $2.323-3.352$ & $<0.001$ \\
\cline { 2 - 5 } Subjective oral health & Bad & 1 & & \\
\cline { 2 - 5 } & Good & 0.426 & $0.363-0.500$ & $<0.001$ \\
\hline Use of floss & No & 1 & & \\
\cline { 2 - 5 } & Yes & 0.628 & $0.510-0.772$ & $<0.001$ \\
\hline
\end{tabular}

Values are presented as number (weighted \%); "calculated by multiple logistic regression analysis

\section{Discussion}

Several countries worldwide have selected representative oral diseases that should be managed in order to improve the oral health of the people by investigating the causes of tooth extraction. In almost all countries, dental caries and periodontal diseases were the main causes of tooth loss [21-23]. Oral disease cannot be fully recovered once it occurs; therefore, proper management is more required as compared to any other diseases [24]. Osteoporosis and osteoarthritis, which are thought to be related to periodontal diseases, are caused by the decrease in bone mass, and may cause bone weakness and fracture. It has also been reported that the reduction of bone mass itself does not cause any symptoms, but once there is a fracture, pain, loss of function, and deformity may occur [25]. There may be some similarities and causal relationships between the two diseases that are expected to increase in the aging society with an increased average life expectancy. Therefore, the purpose of this study is to investigate the factors affecting the prevalence of periodontal diseases and to provide fundamental data for the prevention and maintenance of the oral health of patients with bone disease.

In terms of the prevalence of periodontal diseases according to the income among the general characteristics of the subjects, the prevalence had the tendency to decrease as the income increases from the lower $(46.0 \%)$, lower-middle $(45.1 \%)$, and upper-middle $(30.2 \%)$ to the upper level $(27.9 \%)$. This result was consistent with those of Won et al. [26] and Lee at al. [27]. This is because the higher the income, the better the information acquisition and the better the utilization of medical institutions. Therefore, it is necessary to provide information and opportunities to receive medical services equally for various classes of patients. As for the education level, the prevalence of periodontal diseases had the tendency to become lower as the education level becomes higher at $31.1 \%$ in high 
school graduates and $24.4 \%$ in college graduates or higher. This is similar to the result that the lower the level of education, the lack of knowledge about oral health or lack of awareness for oral disease prevention. In regard to the prevalence of periodontal diseases according to health behavior, the prevalence was high in hypertensive patients, which is similar to the result of the previous study conducted by Cheon et al. [24]. On the other hand, there was no significant outcome in the relationship between the use of oral care products and periodontal diseases in the prevalence of periodontal diseases according to oral characteristics. In this study, although the use of oral care products did not show a statistically significant relationship, it is thought that education on the proper use of oral care products by dental hygienists is urgently needed because continuous and proper use of oral care products will gradually help in the prevention and management of periodontal diseases.

The analysis of relevant variables affecting periodontal diseases in patients with bone disease showed statistically significant results in low income, hypertension, subjective oral health status, and use of dental floss. First, in terms of income, the prevalence of periodontal diseases increased by 1.5 times and 1.3 times, respectively, when the income was lower and lower-middle, as compared to the upper level. The result of this study is similar to those of Won et al. [26] and Cheon et al. [24]. The role of dental hygienists in oral health activities and delivery of oral health information for low-income people can be very important, and the active promotion of measures to intensively manage periodontal diseases in the subjects is necessary. In addition, hypertension is associated with a higher incidence of periodontal diseases (2.790-fold), which is consistent with the results of Baek et al. [28] and Park et al. [29]. Oral health care is essential for all ages in the life cycle. However, patients with hypertension, which is a chronic disease, are more likely to develop periodontal diseases. For this reason, intensive periodontal disease management programs will be needed for hypertensive patients. In patients with a good subjective health status, there is a likelihood of having periodontal diseases lowered to approximately $42.6 \%$ level. In the case of using dental floss, there is a likelihood of having periodontal diseases lowered to approximately $62.8 \%$ level. The use of dental floss seems to prevent periodontal diseases by selectively and intensively managing difficult areas.

This study has a limitation in that it is a cross-sectional study using the raw data of KNHANES VI-3. However, this study has its significance in that it conducted an analysis with the most recent data, and general characteristics, health behavior, and oral characteristics were investigated from multiple aspects.

\section{Conclusion}

In summary, the management of systemic diseases and the use of oral care products are important factors with regard to the prevalence of periodontal diseases in patients with bone disease. This study result ultimately contributes not only to the enhancement of the oral health for patients, but also the improvement of their quality of life by carrying on a healthy lifestyle in an aging society. It is important to develop various programs that deliver information on the prevention and management of periodontal diseases in chronic patients, proper use methods of oral care products, oral health knowledge for low-income people, and the role of dental hygienists who cultivate professional oral care knowledge in the program operation.

\section{Acknowledgments}

This work was supported by Youngsan University Research Fund of 2018.

\section{Conflict of Interest}

The authors report no conflicts of interest related to this study. The author does not have any financial interest in the companies whose materials are included in the article.

\section{References}

1. Hong SA. A study of prevalence and related risk factors of osteoporosis for employees. KICS 2013; 8: 631-637.

2. Kim KM, Kim YJ, Chung HJ. Osteoporotic condition in postmenopausal women with periodontitis. JPIS 2002; 32: 225-234.

3. Hur NW, Choi CB, Uhm WS, Bae SC. The prevalence and trend of arthritis in Korea: results from Korea national health and nutrition examination surveys. J Rheum Dis 2008; 15: 11-26.

4. Hwang SH, Han SS, Yoo WK. The effects of chewing difficulty on the prevalence of osteoarthritis in adults aged 50 years and older. J Dent Hyg Sci 2015; 15: 145-152.

5. Bird DL, Robinson DS: Modern dental assisting. 8thed. Elsevier, St. Louis 2005: 188-196.

6. National Health Insurance. Key statistics analysis results of health insurance in Q1 2011.

7. National health nutrition survey. Ministry of health and welfare centers for Disease Control and Prevention, 2015.

8. Daniell HW. Postmenopausal tooth loss. Contributions to edentulism by osteoporosis and cigarette smoking. Arch Intern Med 1983; 143: 1678-1682.

9. Bras J. Mandibular atrophy and metabolic bone loss. Int Dent J 1990; 40: 298-302.

10. Baxter JC. Relationship of osteoporosis to excessive residual ridge resorption. J Prosthet Dent 1981; 46: 123-125.

11. Baylink DJ, Wergedal JE, Yamamoto K, Manzke E. Systemic factors in alveolar bone loss. J Prosthet Dent 1974; 31: 486-505.

12. Klemetti E. A review of residual ridge resorption and bone density. J Prosthet Dent 1996; 75: 512-514.

13. Kribbs PJ. Comparison of mandibular bone in normal and osteoporotic women. J Prosthet Dent 1990; 63: 218-222. 
14. Mercado FB, Marshall RI, Bartold PM. Inter-relationships between rheumatoid arthritis and periodontal disease. J Clin Periodontol 2003; 30: 761-772.

15. Ishi Ede P, Bertolo MB, Rossa C, Kirkwood KL, Onofre MA. Periodontal condition in patients with rheumatoid arthritis. Braz Oral Res 2008; 22: 72-77.

16. Jang YJ, Kim NS. Community periodontal index and osteoporosis relevance. J Korean Soc Dent Hyg 2012; 12: 943-952.

17. Locker D. Association between clinical and subjective indicators of oral health status in an older adults population. Gerodntology 1994; 11: 108-114.

18. Chang YK, Seo HJ, Jin YW, Joeng MS, Sung SH, Park DY, Kim CS, Kim SG. The prevalence and risk factors of osteopenia and osteoporosis in 40-59 year-old male workers. Korean J Occup Environ Med 2006. 18: 130-137.

19. Dev YP, Khuller N, Basavaraj PGS. Rheumatoid arthritis among periodontitis patients in Baddi industrial estate of Himachal Pradesh, India: a cross sectional study. J Clin Diagn Res 2013; 7: 2334-2337.

20. Detert J, Pischon N, Burmester GR, Buttgereit F. The association between rheumatoid arthritis and periodontal disease. Arthritis Res Ther 2010; 12: 1-7.

21. Morita M, Kimura T, Kanegae M, Ishikawa A, Watanabe T. Reasons for extraction of permanent teeth in Japan. Community Dent Oral Epidemiol 1994; 22: 303-306.

22. Takala L, Utrialousnessinen $P$, Alanen P. Incidince of edentulousness, reasons for full clearance, and health status of teeth before extractions in Finland. Community Dent Oral Epidemiol 1994; 22: 254-257.

23. Frisbee SJ, Chambers CB, Frisbee JC. Association between dental hygiene, cardiovascular disease risk factors and systemic inflammation in rural adults. J Dent Hyg 2010; 84: 177-184.

24. Cheon HW, Yu MS, Choi MH. The association of oral diseases and chronic diseases in Korean adult population. J Korean Soc Dent Hyg 2012; 12: 235-249.

25. Han EY, Rhyu IC, Y.M. Lee YK, Han SB, Choi SM, Shin JY, Yang SM, Chung CP. Relationships between osteoporosis, alveolar bone density and periodontal disease in postmenopausal women. JPIS 2001; 31: 565-571.

26. Won JH, Ha MN. An association of periodontitis and diabetes. J Dent Hyg Sci 2014; 14: 107-113.

27. Lee DH, Lee YH. Association between sleep duration, dental caries, and periodontitis in Korean adults: the Korea national health and nutrition examination survey, 2013 2014. J Dent Hyg Sci 2017; 17: 38-45.

28. Baek HJ, Choi YH, Lee SG, Song KB, Kwon HJ. The association of metabolic syndrome and periodontitis in Korean adult population. J Korean Acad Oral Health 2010; 34: 338-345.

29. Park SP, Park BJ, Kim YJ, Chung HJ. Periodontal status in patients with osteoporosis. JPIS 1999; 29: 41-49.

\section{*Correspondence to}

Seoul-Hee Nam

Department of Dental Hygiene

College of Health Science

Kangwon National University

Republic of Korea 